\title{
0 livro didático brasileiro de Ciências: aproximações e distanciamentos do currículo prescrito ao planejado na temática do Sistema Solar
}

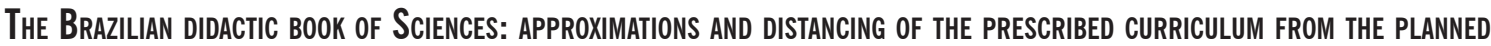
CURRICULUM In the thematic OF the SOLAR SySTEM

\author{
Dérik Mateus Martoneto ${ }^{1}$ \\ 1-Mestrando no Programa de Pós-Graduação em Educação. Centro Universitário Moura Lacerda, Ribeirão Preto, SP, Brasil. E-mal:eng.derik@hotmail.com
}

Abstract: This study aimed to analyze the conformance of the prescribed science curriculum, in relation to the curriculum planned for the student, regarding the thematic of the Solar System. Conformance with the PCNs (National Curricular Parameters) was also assessed. This qualitative research analyzed seven collections of the 6th grade of elementary school II, approved by the PNLD (National Book and Didactic Material Program), regarding the thematic of the Solar System. A documentary analysis was carried out. The author has observed many disparities regarding the subjects addressed in science textbooks, and found no agreement between the presentations contained in teacher manuals and student books. Few books meet the requirements of PCNs for science teaching, showing that science teaching is not neutral and is always under construction. It behooves authors to seek to reaffirm their proposals and meet the objectives of PCNs, seeking to provide a better construction of knowledge in science teaching.

\section{Manuscrito:}

Recebido: 26/09/2017

Corrigido: 06/12/2017

Aceito: $14 / 01 / 2018$

Citation: Martoneto D.M. 2018. 0 livro didático brasileiro de Ciências: aproximações e distanciamentos do currículo prescrito ao planejado na temática do Sistema Solar. Terræ Didatica, 14(2):134-146. URL: http://www.ige. unicamp.br/terraedidatica/.

Keywords: Science teaching, textbook, curriculum, astronomy, Solar System.

\section{Introdução}

Este artigo faz parte de uma pesquisa de dissertação de mestrado, que visa analisar os livros didáticos brasileiros de Ciências do $6^{\circ}$ ano do ensino fundamental II, na temática do Sistema Solar. Particularmente neste trabalho será apresentada como a História da Ciência é introduzida no tocante a apresentação dos modelos geocêntrico e heliocêntrico.

Sendo o livro didático um recurso de uso contínuo nas práticas pedagógicas do professor, compreende-se que o seu estudo possibilita ampliar o entendimento do currículo desenvolvido na escola. De acordo com Gimeno Sacristán (2000), existe uma dependência dos professores em relação a materiais que estruturem o currículo, desenvolvam conteúdos e apresentem estratégias de ensino. É no sentido de instrumento pedagógico que se concebe o livro didático neste artigo.

Para Gimeno Sacristán (1998) o currículo é um processo que envolve vários atores e contextos. No processo curricular há diferentes fases, entre elas: a fase que se dá no contexto das políticas educacionais denominada por currículo prescrito e a fase que é caracterizada pela produção de material didático para o professor, o denominado currículo planejado. Neste sentido, esta análise visa verificar as proximidades e distanciamentos entre o currículo prescrito e o currículo planejado para os professores por meio da comparação entre o que está sugerido nos Parâmetros Curriculares Nacionais de Ciências Naturais (PCNs) e o que consta em livros didáticos de Ciências Naturais para o $6^{\circ}$ ano do ensino fundamental II, aprovados pelo Plano Nacional do Livro Didático (PNLD) de 2017, no tocante a introdução da História da Ciência na temática do Sistema Solar, particularmente em relação a apresentação dos modelos geocêntrico e heliocêntrico.

\section{Fundamentação teórica}

Pesquisadores da área de Ensino de Ciências têm analisado livros didáticos e o uso dos mesmos pelos professores. Amaral (2006) destaca o uso flexível do livro didático pelos professores, pois 
estes têm procurado outras fontes de informações para desenvolver sua prática, tais como jornais, revistas, internet e vídeos. Contudo, para o autor muitos professores ainda são fiéis ao livro didático, tornando-o o principal controlador do currículo. Delizoicov et al. (2011), é contundente na crítica sobre o uso de livros didáticos, pois muitos professores da área de Ciências Naturais ainda permanecem seguindo livros didáticos e, em decorrência disto, muitas vezes ainda o ensino prioriza a memorização de informações isoladas.

Se de um lado há uma crítica pelos pesquisadores da área de Ensino de Ciências sobre o uso do livro didático do outro há pesquisadores que analisaram construtivamente livros didáticos de ciências, o é nossa intenção neste artigo.

Fracalanza \& Megid Neto (2006, p. 94) indicam equívocos encontrados em livros didáticos de ciências analisados e afirmam que o conhecimento científico tem sido apresentado como "produto acabado de algumas mentes privilegiadas, desprovidas de interesses político-econômicos e ideológicos, que apresenta o conhecimento sempre como verdade absoluta, sem contexto histórico e sociocultural". Os autores salientam que o professor pode alterar tal proposta e advertem que os livros têm apresentado o conhecimento científico com supremacia em relação a outras formas de conhecimento, de certa forma apresentando "as ideias de objetividade, neutralidade e verdade absoluta e definitiva", o que indica uma concepção de ciência moderna de raízes cartesianas e positivistas. Acrescentam ainda que os livros não introduzem a História da Ciência mostrando um isolamento da atividade científica.

Outros autores que analisaram livros didáticos tecem críticas ao modo em que a História da Ciência é introduzida nos mesmos. Allchin (2004) faz uma crítica sobre a História da Ciência da forma como é apresentada nos manuais escolares, pois a História da Ciência surge, com frequência, em contextos educativos apresentando uma versão totalmente romanceada e exacerbada. A forma de apresentar o desenvolvimento da Ciência, numa abordagem simplificada, cria condições propícias para que se estabeleçam determinados estereótipos e mitos.

Pereira e Amador (2007, p. 213) verificaram o tipo de utilização atribuída à História da Ciência em manuais escolares de Ciências da Natureza no Ensino Básico Português e concluíram que os manuais apresentam uma quantidade significativa de História da Ciência. Contudo, "na maior parte das situações os conteúdos históricos são apresentados na forma de informação factual e com caráter essencialmente descritivo", como, por exemplo, nas biografias dos cientistas, apresentadas "sem destacar a importância que, nas diferentes épocas, assumiram as observações, modelos e teorias propostas".

Pedrinaci (1994) ao analisar a concepção de ciência em livros didáticos na Espanha concluiu que muitas vezes a ciência tem sido introduzida no ensino de modo a dar uma visão de que é constituída por um conjunto infalível de verdades, de abordagem acabada e de modo a ocultar as incertezas e questões que existiam à época. $\mathrm{O}$ autor considera que a introdução da história da Geologia nos livros didático possibilita a compreensão sobre o relacionamento entre ciência e sociedade, sobre o processo de elaboração da ciência, facilita a compreensão dos conceitos científicos complexos, além de seus significados e utilidades.

Souza et al. (2017) procedem a uma análise das ilustrações no campo da Geociências contidas em livros didáticos da educação básica da Espanha, Itália, Portugal e Brasil, usando como referência o artigo de Pedrinaci et al. (2012), intitulado de "Alfabetização em Ciências da Terra: uma proposta curricular". Os autores tiveram como objetivo verificar as ideias chaves que envolvem a alfabetização em Ciências da Terra, de modo a contribuir na definição das diretrizes de um currículo. Concluíram que mesmo havendo diferenças curriculares nos sistemas educacionais dos países analisados, nota-se que a Espanha, Itália e Portugal, compartilham o fato de possuírem disciplinas e livros específicos para o ensino de Ciências Naturais e, no Brasil, os conteúdos geológicos são abordados nas disciplinas de Física, Química, Biologia e Geografia. Os livros dos quatro países apresentaram algumas inconsistências, tais como os problemas causados pelo uso da linguagem científica - falta de escala, rodapé com dados ausentes ou imprecisos -, além de considerações técnicas/estéticas - falta de perspectivas 3D, qualidade das cores e sombras - e conceitos que induzem a erros conceituais - mistura de gráficos e imagens, ilustrações "desconectados" sem qualquer estímulo verbal (comentários e/ou perguntas).

Diversos pesquisadores da área de Ensino de Ciências alertam que o conhecimento científico tem sido na maioria das vezes apresentado na escola de modo descontextualizado ou contextualizados com diferentes fundamentações e não apresentam o processo de elaboração do conhecimento científico de modo a evidenciar a Ciência como construção humana. 
Complementando tal afirmação, Praia (2012, p. 62) ressalta a importância da educação científica para o desenvolvimento do aluno, não só dentro da escola, mas para o pleno exercício da cidadania, uma vez que "a educação científica tem um papel decisivo, capaz não só de sensibilizar, mas, sobretudo, de fortalecer a consciência de alunos-cidadãos".

Delizoicov et al. (2011, p. 67) destaca que, "é bastante consensual, em todas as propostas curriculares, a veiculação do conhecimento científico e tecnológico não acabado, não neutro, social e historicamente construído", pois considera que uma das funções do ensino de ciências é possibilitar que o aluno compreenda a estrutura do conhecimento científico, seu caráter dinâmico que o impede de ser apresentado como pronto, acabado e verdadeiro, embora as teorias têm sido utilizadas pelo homem para explicação dos fenômenos.

Ao analisar tendências historiográficas atuais, Trindade et al. (2010) indicam que estas não se baseiam na ideia de que o conhecimento científico se dá por acúmulo de ideias antigas ou por revoluções, mas que tanto as rupturas quanto as continuidades são consideradas relevantes, assim como fatores ligados à lógica interna e fatores ligados à economia, à política e à cultura.

Neves (2000, p. 566) ao analisar a história da Astronomia no ensino de ciências, adverte que muitos tendem a recontar a história de modo deturpado, "esquecendo fatos", apresentando apenas a visão dos vencedores. Tece considerações advertindo profissionais que transmitem conhecimentos sobre a importância de recorrerem às fontes "de onde brotam todos os resultados dos paradigmas que hoje abraçamos como supostas verdades dentro da atual Ciência".

No que tange ao ensino de Astronomia na educação básica do Brasil, é muito comum encontrarmos estudos que apontam erros conceituais ou equivocados de Astronomia nos livros didáticos de Ciências. A conclusão da pesquisa de Langhi e Nardi (2007) sobre o levantamento dos problemas mais comuns sobre a temática da Astronomia em livros didáticos aprovados pelo PNLD, revela que há erros conceituais e neste sentido defendem a necessidade de se inserir tópicos de Astronomia na formação inicial ou continuada de professores de modo a instrumentá-los na escolha e correção dos mesmos.

O conteúdo de Astronomia também foi tema de estudo para Amaral \& Oliveira (2011) ao analisarem a Astronomia presentes nos livros didáticos de Ciências do ensino fundamental II aprovados pelo PNLD de 2008. A pesquisa caracterizou-se pela frequência com que alguns conteúdos eram abordados, tais como os textos, as figuras, atividades de experimentação e até mesmo os erros conceituais. A análise revelou que os livros didáticos ainda apresentam muitas limitações e informações imprecisas ou desatualizadas. Lembram os autores que, um professor com formação deficiente no campo da Astronomia, enfrentará dificuldades de identificar os problemas e alguns erros conceituais que os mesmos apresentam.

$\mathrm{Na}$ tentativa de analisar erros nos livros didáticos de ciências, Trevisan et al. (1997) analisaram duas coleções didáticas do ensino fundamental I. De acordo com os autores, os livros didáticos subestimam a inteligência das crianças, pois só pela televisão já recebem as informações contidas nos livros, que muitas vezes as apresentam de forma errada. No manual do professor, os conteúdos também deixam a desejar, não oferecendo informações adicionais, nem estimulam a capacidade de observação dos fenômenos do céu.

Neste sentido, destacamos a importância deste estudo, em avaliar as coleções de livros didáticos aprovados pelo PNLD de 2017, na intenção de contribuir e auxiliar os professores de Ciências, mostrando a importância da História da Ciência no processo de ensino e aprendizagem de conhecimentos científicos, na temática da evolução do Sistema Solar.

De acordo com tal referencial foram desenvolvidos os procedimentos metodológicos.

\section{Procedimentos Metodológicos}

Esta pesquisa é uma análise documental de natureza qualitativa. Como define Cellard (2008, p. 295), em relação a análise de documentos, o livro didático constitui "um documento escrito e, portanto, uma fonte importante para todo pesquisador, [...] não é raro que ele represente a quase totalidade dos vestígios da atividade humana em determinadas épocas". Sendo a análise documental reconhecida como uma pesquisa de vantagens significativas, para o autor (Cellard, 2008, p. 295), "trata-se de um método de coleta de dados que elimina, a eventualidade de qualquer influência - a ser exercida pela presença ou intervenção do pesquisador".

Tendo em vista a importância do livro didático no processo curricular, como já enunciado anteriormente, a análise documental se procedeu em duas partes, ou seja, analisou-se o currículo prescrito e o currículo planejado para o professor. 
Para analisar o currículo prescrito foi selecionado como documento oficial os Parâmetros Curriculares Nacionais de Ciências Naturais (1998) de âmbito federal, no qual foram analisados trechos referentes à introdução da História da Ciência no ensino de Ciências e as sugestões para o ensino da evolução do Sistema Solar no contexto dos conteúdos de Astronomia.

Para compreender o currículo planejado para o professor, selecionou-se 7 coleções de livros didáticos das 13 coleções aprovadas pelo PNLD de 2017.

Serviu-se de uma análise documental, como define Cellard (2008, p. 296), o trabalho com documentos "deve superar vários obstáculos e desconfiar de inúmeras armadilhas, antes de estar em condição de fazer uma análise em profundidade de seu material".

O recorte deste artigo está voltado para analisar livros do $6^{\circ}$ ano do ensino fundamental II, no tocante ao estudo da evolução do Sistema Solar. Os livros escolhidos para análise foram nomeados de L1, L2, L3, L4, L5, L6 e L7, conforme apresentado na Tab. 1.

Após a seleção e escolha dos livros didáticos, foram examinados os capítulos que trataram da temática do Sistema Solar, fazendo a análise de todo o seu conteúdo, juntamente com as considerações contidas no manual do professor, quando este existia.

\section{Resultados}

A análise esteve pautada em dois temas: a coerência entre as intenções manifestas pelos autores e o conteúdo voltado para a temática do Sistema Solar e as proximidades e distanciamentos com o currículo prescrito nos Parâmetros Curriculares Nacionais de Ciências Naturais do ensino fundamental.

\section{0 currículo prescrito para o ensino de Ciências Naturais: a questão da História da Ciência}

Os Parâmetros Curriculares Nacionais são dirigidos aos professores com objetivo de contribuir para o planejamento de seu trabalho, indicando parâmetros para a o ensino das diferentes disciplinas tendo em vista a construção do projeto pedagógico da escola e do sistema de ensino do qual faz parte (Brasil 1998).

Desde meados da década de 1980, diversos especialistas vêm preconizando uma reorganização drástica na estrutura programática do currículo de Ciências no ensino fundamental.

Consta dos Parâmetros Curriculares Nacionais de Ciências Naturais (1998) que o objetivo do ensino de Ciências Naturais é

[...] mostrar a Ciência como elaboração humana para uma compreensão do mundo [...]. Seus conceitos e procedimentos contribuem para o questionamento do que se vê e se ouve, para interpretar os fenômenos da natureza, para compreender como a sociedade nela intervém utilizando seus recursos e criando um novo meio social e tecnológico. [...] desenvolvimento de postura reflexiva e investigativa, de não-aceitação, a priori, de ideias e informações, assim como a percepção dos limites das explicações, inclusive dos modelos científicos, colaborando para a construção da autonomia de pensamento e de ação (p. 22-23).

Um dos objetivos da aprendizagem de Ciências Naturais no ensino fundamental "é dar condições para o aluno vivenciar o que se denomina método científico, ou seja, a partir de observações, levantar hipóteses, testá-las, refutá-las e abandoná-las quando fosse o caso" (Brasil 1998 , p. 20)

Tabela 1. Livros didáticos analisados com autoria, editora e ano

\begin{tabular}{|c|c|c|c|c|}
\hline Livro & Nome do Livro & Editora & Autor (es) & $\begin{array}{c}\text { Ano de } \\
\text { publicação }\end{array}$ \\
\hline 1 & Universos: Ciências da Natureza & SM & Lia Monguilhott Bezerra & 2015 \\
\hline 2 & Projeto Teláris: Ciências & Editora Ática & Fernando Gewandsznajder & 2016 \\
\hline 3 & Tempo de Ciências & Editora do Brasil & Ângela Sillos e Eduardo Passos & 2015 \\
\hline 4 & Ciências & Quinteto & $\begin{array}{c}\text { José Trivellato, Sílvia Trivellato, } \\
\text { Marcelo Motokone, Júlio Foschini } \\
\text { Lisboa e Carlos Kantor }\end{array}$ & 2015 \\
\hline 5 & $\begin{array}{l}\text { Investigar e Conhecer: Ciências } \\
\text { da Natureza }\end{array}$ & Saraiva Educação & Sônia Lopes & 2015 \\
\hline 6 & Ciências Novo Pensar & FTD & $\begin{array}{c}\text { Demétrio Gowdak e Eduardo Mar- } \\
\text { tins }\end{array}$ & 2015 \\
\hline 7 & Projeto Apoema: Ciências & Editora do Brasil & $\begin{array}{c}\text { Ana Maria Pereira, Margarida Santa- } \\
\text { na e Mônica Waldhelm }\end{array}$ & 2015 \\
\hline
\end{tabular}


Os PCNs, como currículo prescrito para a educação fundamental em âmbito nacional, consideram que é importante apresentar a Ciência como construção humana e não como "verdade natural". Neste sentido, há um destaque para a introdução da História e Filosofia da Ciência no processo educacional no sentido de introduzir o processo de construção do conhecimento científico no ensino.

Tendo em vista o recorte deste artigo, chama atenção que consta dos PCNs (1998, p. 90) a importância de explicitar para o aluno as razões da mudança dos modelos de Sistema Solar. Assim está expresso que os alunos devem "compreender como as teorias geocêntrica e heliocêntrica explicam os movimentos dos corpos celestes, relacionando esses movimentos a dados de observação e à importância histórica dessas diferentes visões". Consta ainda que a partir do quarto ciclo, é possível e desejável que se desenvolva com os estudantes o significado histórico da ruptura entre o modelo geocêntrico de universo e o modelo heliocêntrico do Sistema Solar para o pensamento ocidental.

\section{0 currículo planejado para os professores nos livros didáticos de Ciências Naturais}

\section{Coleção L1}

Ao realizar uma leitura exploratória no sumário, das cinco unidades presentes no livro do sexto ano, a primeira é destinada ao estudo da "Terra e Universo", objeto de nossa análise, pois consta da mesma a temática do Sistema Solar. Nesta unidade, tal temática é contemplada no segundo capítulo denominado "Sistema Solar".

O referido capítulo foi iniciado por meio de uma foto do atual modelo heliocêntrico, seguida por uma longa descrição de todos os planetas e do Sol. Destaca-se que os modelos do Sistema Solar foram contemplados e que apresenta elementos da História da Ciência.

Tal temática foi iniciada por um texto introdutório do qual consta que, "à medida que novas teorias vão sendo testadas e validadas, os modelos até então vigentes acabam sendo alterados" (Bezerra 2015, p. 29). A autora acrescenta ainda que há uma evolução do conhecimento científico do que decorre que "[...] os modelos científicos são mutáveis, [...] as observações têm extrema importância no processo de construção e aprimoramento de modelos explicativos para a natureza e a dinâmica do Sistema Solar" (Bezerra 2015, p. 29).
Na descrição do modelo geocêntrico, que considera a Terra no centro do Universo, a autora destaca dois filósofos que foram importantes à época, Aristóteles, na Grécia Antiga, e o de Ptolomeu, no século II d.C. Como descreve a autora

O modelo de Aristóteles afirmava que havia duas
regiões diferentes: o mundo supralunar e o mun-
do sublunar. Nesse modelo, o mundo abaixo da
Lua, mutável, era formado pelos elementos terra,
ar, fogo e água; já o mundo acima da Lua, perfeito
e imutável, era onde se encontravam os corpos
celestes, os quais, acreditava-se, eram formados
por um quinto elemento: o éter.

Já no século II d.C., Ptolomeu elaborou um modelo aperfeiçoando o modelo geocêntrico proposto na Grécia Antiga. Seu modelo, que dedicava especial atenção ao movimento dos planetas, perdurou por vários séculos (Bezerra 2015, p. 29).

Embora a autora tenha introduzido a descrição dos dois modelos geocêntricos eles não foram introduzidos no texto elementos que pudessem levar o aluno a compreender quais as mudanças nas ideias que fundamentam o modelo proposto por Ptolomeu.

Quanto ao modelo heliocêntrico, que considera o Sol no centro do Universo, a autora destaca apenas a contribuição de Nicolau Copérnico, em meados do século XVI. Entretanto, como no modelo geocêntrico, não questionaram o motivo de Nicolau Copérnico desenvolver o heliocentrismo, não introduzindo no texto os argumentos que o levaram a questionar o modelo anterior. Mas considera-se que há um esforço em se aproximar dos PCNs ao introduzir as mudanças nos referidos modelos.

É importante destacar que só há breve menção ao contexto da época, referindo-se ao papel da Igreja Católica que apoiava o modelo geocêntrico, embora no manual do professor a autora tenha sugerido que o professor promova uma reflexão junto aos alunos sobre o contexto em que se deu a quebra desse paradigma.

Pode-se concluir que o livro didático introduz a História da Ciência no capítulo do Sistema Solar, apresentando proximidades com os PCN, entretanto, de modo a não fornecer elementos suficientes para que o aluno compreenda o processo de desenvolvimento da ciência. 


\section{Coleção L2}

Neste livro do $6^{\circ}$ ano do ensino fundamental, o autor apresenta quatro unidades, sendo elas: "os seres vivos e o ambiente", "as rochas e o solo", "a água" e "o ar e o universo". Na abertura de cada unidade, o autor procura despertar o interesse do aluno na seção "Ponto de partida", buscando destacar aspectos que serão desenvolvidos na unidade. Ao final de cada uma delas, apresenta a seção "Ponto de chegada", que nada mais é que uma síntese do que deve ter sido aprendido pelo aluno. O autor considera que os alunos devem ser capazes de identificar e relatar para que serve, do ponto de vista social, esse aprendizado (Gewandsznajder 2016).

Ao longo dos capítulos, aparecem boxes "Ciência e história", "Ciência e sociedade", "Ciência e tecnologia", "Ciência e saúde" e "Ciência e ambiente".

Um dos objetivos destacados pelo autor, no manual do professor, para o efetivo ensino de Ciências da Natureza é:

Compreender que a ciência não é um conjunto de conhecimentos definitivamente estabelecidos, mas que se modifica ao longo do tempo, buscando sempre corrigi-lo e aprimorá-los; desenvolver o pensamento lógico e o espírito crítico para identificar e resolver problemas, formulando perguntas e hipóteses, aplicando os conceitos científicos a situações variadas, testando, discutindo e redigindo explicações para os fenômenos naturais [...] (Gewandsznajder 2016, p. 269).

Neste sentido, pode-se perceber que o autor indica a importância da apresentação da história para o ensino de Ciências da Natureza.

Fazendo uma leitura exploratória no sumário do livro, selecionou-se o capítulo 16, intitulado de "O Sistema Solar", para análise. Dentro deste capítulo, há um texto intitulado de "O Sol e os planetas", onde o livro trata de modo sucinto a origem do Sistema Solar. Contudo, nota-se a ausência da abordagem do modelo geocêntrico e heliocêntrico e sua construção como conhecimento científico, apontando os desafios e dificuldades de cada época em seu contexto histórico, desde a época de Aristóteles até os dias atuais.

O autor faz uma abordagem minuciosa de cada planeta, junto de sua respectiva imagem, apontando suas características tais como diâmetro, período de rotação e a quantidade de satélites, se for o caso de possuir, o que vai na direção contrária do sugerido nos PCNs de Ciências Naturais, ou seja, consta do referido documento que a comparação entre planetas do Sistema Solar pode ser útil, mas "longe de requerer descrições minuciosas, este estudo deve revelar que os planetas têm características muito diferentes da Terra" (p. 65), uma vez que "o objetivo não é saber os nomes dos astros, embora alguns alunos gostem” (p. 65).

No capítulo 16 não há nada que sugira a abordagem do modelo geocêntrico e suas complicações, tampouco o modelo heliocêntrico e os filósofos que contribuíram na construção dos mesmos. A História da Ciência foi deixada de lado, não há a abordagem de uma evolução dos conceitos e da prática científica.

No box "Ciência e História" do capítulo 16, o autor aborda a história de Plutão e as decisões que levaram ao seu rebaixamento como planeta. Não consta no livro do aluno, nem no manual do professor, os objetivos específicos dos boxes contidos no livro.

Embora o autor defenda na introdução do livro que é importante apresentar a História da Ciência no ensino de Ciências de modo a demonstrar a provisoriedade do conhecimento científico no tópico relacionado ao estudo do Sistema Solar, esta não foi contemplada, pois não foram introduzidos os modelos geocêntrico e heliocêntrico e nem mesmo citados os pensadores que os formularam. Pode-se concluir que o livro não apresenta coerência interna e não se aproxima dos PCNs no tocante ao estudo dos modelos do Sistema Solar.

\section{Coleção L3}

Neste livro, Tempo de Ciências, o conteúdo está organizado em oito temas, contendo de cinco a seis capítulos em cada tema. No tema um, intitulado "Nosso lugar no Universo", está o conteúdo de nosso interesse e, dentro desse tema, no capítulo dois, "Sistema Solar".

$\mathrm{Na}$ seção "Explorando os movimentos da Terra", os autores propõem uma reflexão sobre o movimento de revolução da Terra, abordando o diálogo de uma aluna que questiona o movimento da Terra ao redor do Sol. Em uma de suas inquietações, ela diz "ah, como se explica essa ideia de o Sol não girar em torno da Terra? Para mim, os gregos é que estavam certos!" (p. 18). O questionamento da personagem se refere ao modelo geocêntrico, em que a Terra ocupa o centro do Sistema Solar e os astros giram ao seu redor. 
O questionamento que a personagem faz sobre o movimento da Terra é similar à situação-problema que os PCNs de Ciências Naturais expõem em que "o modelo de céu construído espontaneamente pelo aluno tem a Terra como ponto de referência central" (p. 62). No manual do professor, os autores recomendam embasar a discussão utilizando o texto "Em torno de quê? O Geocentrismo e o Heliocentrismo", disponível em site para consulta (Passos \& Sillos 2015).

O texto sobre a história da evolução do modelo planetário se inicia com o geocentrismo de Aristóteles com base na observação do céu e dos astros, em raciocínio lógico e em cálculos. Em seguida é apresentado Claudius Ptolomeu, também como defensor do geocentrismo. Porém, a sua contribuição e os seus questionamentos à época, não são mencionados.

O texto se encerra apresentando Nicolau Copérnico como defensor do heliocentrismo, "apenas no século XVII uma nova concepşão veio abalar o chamado geocentrismo" (p. 20).

As ideias de Copérnico foram aprimoradas pelo cientista italiano Galileu Galilei, primeira pessoa a apontar uma luneta para o céu, e os estudos relativos ao modelo heliocêntrico e o conhecimento sobre o lugar ocupado pelo Sol e pela Terra no Universo foram ampliadas. Sabemos, atualmente, que o Sol é o centro do nosso sistema planetário, denominado Sistema Solar, mas não é o centro do Universo" (p. 20).

Nesta seção pode-se concluir que há uma proximidade com o que é prescrito nos PCNs, de modo a mostrar a evolução das ideias científicas.

$\mathrm{Na}$ seção "Ciência e Sociedade", os autores fazem uma abordagem interessante da influência da tecnologia para a Astronomia, "com o auxílio de instrumentos, os cientistas puderam observá-lo com mais precisão, descobrir novos astros e galáxias, elaborar modelos que descrevem como ele funciona e conhecer melhor nosso Sistema Solar" (p. 20). Seguindo a mesma linha do aprimoramento ao projeto da luneta de Galileu Galilei, os autores explanam que

"Galileu observou que o planeta Júpiter tinha luas que giravam em torno dele. Esse fato trouxe problemas para os defensores do geocentrismo que todos os corpos celestes giravam em torno da Terra" (p. 21).

De acordo com os PCNs de Ciências Naturais, o uso de instrumentos e da tecnologia à época, "bem como a forma como foram obtidas, podem ser interessantes para construir imagens do Universo e de sua investigação" (p. 64).

No manual do professor, a temática se aproxima do proposto, pois essa seção aborda

"como ocorre a produção do conhecimento científico, levando os alunos a compreender como um mesmo fenômeno pode ser observado sob diferentes óticas, sendo isto o que faz os cientistas sempre reverem suas teorias" (Passos \& Sillos 2015, p. 284).

Como os PCNs de Ciências Naturais sugerem, essas "relações entre ciência, tecnologia e sociedade não devem ser apresentadas como o triunfo do certo sobre o errado, ou da ciência sobre a religião" (p. 94). Para os PCNs de Ciências Naturais, mais importante que isso, é

“(...) estimular a discussão sobre a superação a que estão submetidas as ideias científicas, o que torna discutível a verdade científica, bem como as responsabilidades sociais envolvidas nas pesquisas descobertas" (p. 94).

No entanto, o desafio dos defensores do heliocentrismo, como Copérnico e Galileu Galilei, é a aceitação dessa ideia pelas instituições sociais, como a Igreja Católica,

"que defendia a Terra como centro do Universo, e não aceitou as demonstrações de Galileu, condenando esse cientista à prisão domiciliar e proibindo-o de divulgar sus ideias" (p. 21).

Pode-se concluir que o livro se aproximou do que é proposto no manual do professor e dos PCNs, apesar de não mostrar a Ciência como construção humana e de caráter não neutro, valeu-se da tentativa de sua aproximação.

\section{Coleção L4}

Esta coleção é composta por nove unidades que são subdivididas em capítulos. As unidades de interesse para este artigo são a unidade oito, intitulada de "Movimentos da Terra" e a unidade nove - "O Sistema Solar e além".

$\mathrm{Na}$ seção "Explore", há um texto intitulado "Geocentrismo x heliocentrismo". Os autores iniciam a abordagem com as ideias de Ptolomeu como sendo "um marco na história da Astronomia" (Trivellato et al. 2015, p. 188), apresentando em seguida a ima- 
gem do modelo geocêntrico com a Terra no centro do Universo. Segue a linha do tempo com a contribuição de Nicolau Copérnico ao heliocentrismo, destacando que "a Terra não era o centro do Universo, mas se deslocava como os demais planetas ao redor de outro astro, o Sol" (Trivellato et al. 2015, p. 188). Apesar da seção trazer o texto como leitura complementar, nota-se uma ausência da razão que levou Nicolau Copérnico a pensar que o Sol estaria no centro do Universo e não a Terra. Apontam que na "representação de Copérnico, é o Sol que está parado no centro do Universo e não mais a Terra, como afirmavam os outros pensadores" (Trivellato et al. 2015, p. 188).

Embora os autores descrevam as características dos dois modelos, não apresentam a transição das ideias que sustentam o novo modelo. Deve-se destacar que consta no manual do professor a importância de abordar a História da Ciência para o desenvolvimento do saber científico do aluno, mostrar essa "provisoriedade do conhecimento científico e o fato de que ele é fruto de uma construção coletiva, embora o trabalho de determinado cientista seja preponderante na formulação de um novo modelo explicativo" (Trivellato et al. 2015, p. 250)

A análise do livro evidencia uma proximidade com os PCNs ao introduzir os modelos e a evolução dos mesmos, entretanto se distancia no tocante a não explicitar as razões para tais mudanças.

Os autores fazem um breve comentário das crenças religiosas à época, "que causaram grande polêmica", mas nada que aprofunde ou deixe bastante esclarecido para o aluno.

Na seção "Para ler o texto científico" (p. 205), os autores apresentam um trecho de um livro que aborda a temática da Terra girante, o título do texto é "Quando pulamos, por que não descemos em outro lugar?". O texto aponta as controvérsias e os dilemas que polemizaram o século XVII. Em um trecho, nos apontam

Se a Terra girava, uma pessoa que pulasse verticalmente no ar pousaria a uma pequena distância de onde partira, posto que o planeta girara sob ela; se atirássemos uma bola verticalmente no ar, esta pousaria a uma distância ainda maior do ponto de partida; e um pássaro que se afastasse de seu ninho não conseguiria encontrá-lo de novo. Como nada disso acontecia, a terra não podia estar em movimento, concluíam (Trivellato et al. 2015, p. 205).

Em outro texto, que está em um box à direita da página, os autores apontam Galileu Galilei como um dos defensores da Terra girante. Neste texto, notamos uma breve definição de Ciência como construção humana, assim como sugerem os PCNs.
O texto mostra uma situação comum nas Ciências: o confronto entre duas teorias. Os defensores de uma das teorias procuram argumentos que mostrem a falsidade da ou- tra, enquanto estes procuram se defender, buscando falhas nas argumentações dos opo- sitores. Galileu desqualificou os argumentos apresentados contra a teoria da Terra girante apontando uma situação experimental que contrariava as previsões que esses argumentos estabeleciam (Trivellato et al. 2015, p. 205).

A unidade nove, em seu primeiro capítulo, recebe o nome de "O Sistema Solar e além". Ao abordar o assunto, os autores fazem uma descrição minuciosa de cada planeta de nosso Sistema Solar, citam os planetas anões e definem o que são meteoros, meteoroides, cometas e asteroides. Contudo, nosso objeto de interesse está no capítulo dois dessa mesma unidade, na seção "Fórum". Levando o nome de "As ideias científicas e as religiões", o texto traz a história de Giordano Bruno, "sendo um dos mais comoventes episódios na história da luta do ser humano pela liberdade de pensar e de se expressar" (p. 231), de sua trajetória, ao defender o heliocentrismo, e de sua batalha com a Igreja Católica. O fato de Giordano Bruno ter sido acusado de heresia, condenado e queimado vivo em praça pública pelo Tribunal da Santa Inquisição, chama a atenção para a controvérsia apontada junto ao contexto religioso que, de uma certa forma, dificultava o avanço da ciência. O texto faz uma abordagem que contempla um dos objetivos do ensino de Ciências Naturais na aprendizagem significativa dos alunos que, como aponta os PCNs, há a necessidade de "valorizar a disseminação de informações socialmente relevantes aos membros da sua comunidade" (p. 89). Também está de acordo com o manual do professor, no item em que os autores definem os objetivos da seção "Fórum", como "o intuito de debater assuntos que têm uma dimensão de controvérsia ou problemática e que envolvem conhecimentos relativos às Ciências Naturais e também outras áreas" (p. 255).

O livro apresenta uma abordagem coerente com o que é proposto no manual do professor e o explorado no livro do aluno, não há discrepância e isso corrobora com o trabalho do professor ao programar e elaborar melhor suas aulas. $\mathrm{Na}$ comparação com as proximidades com os PCNs, 
considera-se sua abordagem satisfatória, uma vez que o livro expôs diversos itens mostrando a ciência como construção humana, além de controvérsias e desafios enfrentados por cientistas ao expor suas ideias de acordo com o contexto da época.

\section{Coleção L5}

Neste livro, o recorte da análise está na unidade um, denominada "Astronomia", que contempla dois capítulos de nosso interesse; o capítulo um é denominado de "A Terra e o céu" e o dois de "Corpos celestes".

A autora inicia o capítulo um com a seção "Voz e vez", com uma atividade que explora o atlas e o globo terrestre que, de acordo com a mesma, "o aluno responderá algumas questões sobre o assunto que será estudado e poderá, com o professor, verificar seus conhecimentos prévios sobre o assunto" (p. 4).

O texto seguinte à seção, intitulado de "Ponto de vista", faz uma abordagem histórica do estudo da Ciência e da Astronomia, sendo "a mais antiga das ciências" (Lopes 2015, p. 19).

No que tange as observações do céu, a autora faz uma explanação dos primeiros registros, ressaltando que os mesmos "datam aproximadamente 3000 anos antes de Cristo e foram feitos por chineses, babilônios, assírios e egípcios. Os astros eram estudados para medir o tempo e para determinar a melhor época de plantio ou colheita" (Lopes 2015, p. 19).

Na página 24, um texto intitulado de "Modelos" chamou a atenção, pois, apesar do livro não fazer referência, o texto aparenta ser de leitura complementar. Nele, a autora faz referência ao modelo de Sistema Solar.

O primeiro modelo que descrevia a rotação da Terra e considerava que o movimento dos astros no céu é aparente foi desenvolvido na Grécia Antiga por Aristarco, que viveu entre 320 e 250 a.C. O modelo de Ptolomeu [...], porém, que considerava a Terra fixa, tornou-se mais amplamente aceito porque era também o adotado por Aristóteles [...]. A influência das ideias de Aristóteles foi grande no meio científico durante muitos séculos” (Lopes 2015, p. 24).

Em seguida, a autora explana a contribuição de Nicolau Copérnico (Lopes 2015, p. 24), que

elaborou um modelo que retomava a ideia de Aristarco: a Terra em movimento de translação, ou seja, deslocando-se em órbita ao redor do Sol. Segundo o modelo de Copérnico, o Sol e outros astros celestes não estavam fixos em uma esfera celeste, mas a Terra e outros planetas estariam em órbita ao redor do Sol. O modelo de Copérnico causou muita polêmica, e alguns de seus defensores foram punidos pela Igreja, que naquela época tinha grande influência na política e na sociedade.

Um dos objetivos propostos pelos PCNs para o ensino de Ciências, é o de "confrontar as diferentes explicações individuais e coletivas, reconhecendo a existência de diferentes modelos explicativos na Ciência, inclusive de caráter histórico" (p. 90), assim como a autora expõe no texto.

O texto finaliza ressaltando a polêmica que os defensores do modelo heliocêntrico enfrentaram diante às imposições da Igreja Católica, devido a sua influência e poder que se instalara àquela época. Ao lado do texto há uma reprodução da imagem do modelo heliocêntrico de Copérnico.

No manual do professor, um dos "conteúdos conceituais" definidos pela autora para a aprendizagem deste capítulo é "a importância dos modelos e as contribuições dos trabalhos de Ptolomeu, Copérnico e Galileu para o desenvolvimento da astronomia" (p. 416) e, um dos "conteúdos atitudinais" é a "valorização da História da Ciência, reconhecendo a importância do conhecimento astronômico de filósofos e cientistas do passado" (p. 417). Contudo, notamos que a descrição dos modelos de Sistema Solar não contempla o proposto no manual do professor, tampouco a valorização da História da Ciência.

No capítulo dois, o assunto de movimentos aparentes dos corpos celestes ainda prevalece. Contudo, na seção "Integração", um texto faz referência às observações do céu feitas pela cultura indígena. De acordo com a autora, esta seção tem o objetivo de "integrar o conteúdo do capítulo com outras áreas do conhecimento, trazendo informações complementares" (p. 5). Em uma passagem do texto ela ressalta que, "em seu cotidiano, realizam tarefas como a caça, a pesca, a lavoura, e vivem em contato muito próximo com fenômenos e componentes da natureza" (p. 35).

Novamente, fazendo uma leitura exploratória no manual do professor, o capítulo dois tem por um de seus objetivos atitudinais, o "estímulo ao desenvolvimento do pensamento crítico" e a "valorização do conhecimento astronômico de cientistas do passado" (p. 420). Neste último quesito, pode-se fazer referência ao pensamento de Aristóteles e Claudius Ptolomeu ao defender o modelo geocêntrico de Sistema Solar e, também à cultura indígena, por suas observações do céu. 
Na seção "Construir e aplicar", a autora propõe atividades, que tem o objetivo de "resgatar os conhecimentos que o educando adquiriu até então" (p. 7). Uma das atividades propostas, sugere ao aluno que pesquise as principais descobertas e contribuições de Ptolomeu; noutra é proposto que o aluno descubra mais cientistas que estudaram e observaram constelações e galáxias na "história da humanidade", elaborando vossas bibliografias (p. 56). Apesar de ir ao encontro do planejamento de atividades propostos pelos PCNs, "como exploração bibliográfica" (p. 116), entende-se que a atividade buscou sanar lacunas provenientes do conteúdo proposto nos capítulos um e dois, uma vez que poucos cientistas são abordados pela autora, dando a entender que poucos são os que contribuíram para a construção do modelo de Sistema Solar.

Conclui-se que o livro responde bem as propostas dos PCNs, desde os objetivos que contempla o ensino de ciências, até as abordagens dos conteúdos que devem ser ensinados aos alunos. No entanto, as propostas contidas no manual do professor não se aproximam do que foi proposto ao aluno. No que tange a formação do Sistema Solar e seus modelos, o livro faz uma exploração superficial.

\section{Coleção L6}

O livro 6 é composto por 16 capítulos que são distribuídos, de forma não linear, em suas cinco unidades. A coleção, segundo os autores, tem como principal objetivo, "permitir aos alunos que correlacionem seu dia a dia com o conhecimento científico" (p. 287).

A primeira unidade é "Astronomia" e possui apenas um capítulo, que leva o nome de "Conhecendo o Universo". Em sua abertura, de duas páginas, os autores lançam três questões sobre Astronomia: a primeira questiona as observações das antigas civilizações em "Por que você acha que povos antigos se dedicavam ao estudo da Astronomia?"; a segunda questão é sobre o telescópio Hubble, que orbita a Terra capturando diversas imagens do universo, em "De que modo Hubble pode ajudar os cientistas a entender melhor o Universo?"; e a terceira questão traz a seguinte reflexão: "Você já imaginou se há vida em outros lugares do Universo?". Essas questões "são acompanhadas de imagens ou textos instigantes $e$, às vezes, de experimentos simples. As questões levantadas são retomadas posteriormente" (p. 288).

Na página seguinte, no texto "Era uma vez a astronomia", no trecho que trata sobre a Grécia, os autores o iniciam com Tales de Mileto, seus estudos na previsão do eclipse solar e o conhecimento do diâmetro da Terra, pouco antes do nascimento de Cristo.

À direita da página, há uma imagem do modelo geocêntrico elaborado por Ptolomeu, "propondo que em torno da Terra, considerada o centro Universo, girariam o Sol, os planetas e as estrelas conhecidas na época" (p. 15).

A breve abordagem do modelo heliocêntrico se inicia com base em estudos realizados "ainda sem a utilização de instrumentos de observação do céu" (p. 15). De acordo com Nicolau Copérnico, "o Sol estava no centro do Universo e a Terra e os demais corpos celestes girariam em torno dele" (p. 15). A ilustração do heliocentrismo de Copérnico está à direita do texto. No manual do professor, constam algumas considerações dos autores sobre os objetivos do ensino de ciências, como "a busca de informações sobre os fenômenos, ultrapassando o conhecimento intuitivo e o senso comum" (p. 277), uma vez que "a aprendizagem de conceitos nunca pode ser considerada acabada, sempre será possível sua ampliação que permitam outras elaborações" (p. 278). No entanto, nota-se a abordagem dos conteúdos do Sistema Solar e a evolução dos modelos do geocentrismo para o heliocentrismo de maneira pronta e acabada, reforçando as ideias do senso comum dos alunos.

A utilização de instrumentos no estudo da observação do céu e da Astronomia é destacada com a luneta de Galileu Galilei, "que descobriu um novo universo inimaginado, totalmente desconhecido à época [...], tais como montanhas e crateras na Lua e que a forma desta não era perfeita" (Gowdak \& Martins 2015, p. 25). Os autores destacam a descoberta de "novos planetas" ao redor de Júpiter, como sendo o maior feito de Galileu Galilei à época.

No que se refere ao seu posicionamento em favor do modelo heliocêntrico, Galileu Galilei foi "perseguido pela Igreja, sendo condenado a abjurar publicamente tudo o que defendera ferozmente" (p. 26). Uma vez condenado, Galileu Galilei passou o resto da sua vida em prisão domiciliar.

No manual do professor, os autores fazem referências a alguns objetivos dos PCNs, como "identificar relações entre conhecimento científico, produção de tecnologia e condições de vida, no mundo de hoje e em sua evolução histórica" (p. 277). Mais adiante, os autores explanam os objetivos específicos propostos pelos PCNs para o terceiro ciclo, que contemplam os sextos e sétimos anos do ensino fundamental, tais como "compreender que a construção do conhecimento, individual e coletiva, ocorre pelo confronto de diferentes 
explicações, em um trabalho constante de reelaboração de ideias e interpretações" (p. 281). Apesar de constar esses objetivos para o ensino de ciências no manual do professor, à luz dos PCNs, observou-se que, na temática dos modelos de Sistema Solar, não há correlação com os mesmos.

O livro propõe muitos exercícios para o aluno, na seção "Rever e Aplicar" são 11 exercícios. O exercício dois faz uma ligação do uso da tecnologia com a Astronomia. Assim propõe os autores (Gowdak \& Martins 2015, p. 23),

[...]. Ela traz um exemplo de como a tecnologia criada pelo ser humano foi capaz de auxiliar no avanço da Ciência. Esse avanço pode acabar nos trazendo novas descobertas, que podem até desconstruir ideias até então consideradas corretas. Pensando nisso, você consegue citar um exemplo de uma ideia sobre astronomia que se mostrou errada com o desenvolvimento do conhecimento científico?

Os PCNs fazem uma referência sobre a importância da tecnologia e do seu uso, levando em consideração o contexto que estamos analisando e os processos que possibilitam essas transformações, "no presente e no passado, no Brasil e no mundo, em vários contextos culturais, considerando-se as alterações que o acesso e o uso da tecnologia promovem no meio social" (p. 48).

$\mathrm{Na}$ questão cinco, os autores perguntam sobre as descobertas de Ptolomeu, Copérnico e Galileu, organizando as informações em um quadro e, na questão seis, os autores querem saber "por que os cientistas da época eram vistos como bruxos?” (p. 24).

Outra questão interessante faz referência às ideias de Galileu Galilei e uma breve reflexão sobre o processo de elaboração do conhecimento científico como consta do texto: "é muito comum que uma teoria seja aceita por determinado período e, depois, com o avanço dos estudos e do conhecimento, seja substituída por outra" (p. 26). São propostos três itens para o aluno responder sobre o assunto.

O livro não traz muitas orientações no manual do professor que possa contribuir como complemento para as aulas do professor. Nas poucas orientações que foram possíveis observar, notou-se um distanciamento entre a proposta do ensino de ciências e o que é explorado no livro do aluno, na temática da evolução do pensamento sobre o Sistema Solar. Entendeu-se que, a quantidade de questões propostas para o aluno, nessa mesma temática, buscou complementar algumas lacunas que não foram contempladas nos textos analisados no livro do aluno.

\section{Coleção L7}

Neste livro, que de acordo com as autoras "trata de vida", distribuiu-se os quinze capítulos que o compõe em cinco unidades. $\mathrm{Na}$ intenção de "articular o que você aprenderá com seu dia-a-dia”, nossa unidade de interesse foi a de número cinco, que leva o nome de "A Terra e o Universo". A unidade cinco é composta pelos capítulos treze (O Universo), catorze (Sistema Solar) e quinze (A Terra e a Lua). Nosso recorte será na análise dos capítulos catorze e quinze.

Em uma leitura exploratória por esses dois capítulos notou-se que a História da Ciência surge no capítulo quinze, contudo, o Sistema Solar é abordado no capítulo catorze. Discorreu-se a análise do capítulo catorze e em seguida a do capítulo quinze.

O texto que inicia o capítulo catorze tem o nome de "O surgimento do Sistema Solar", onde as autoras lembram que "num dos braços da Via Láctea está situado o Sol, uma de suas estrelas, em torno do qual se movem vários astros, entre eles a Terra, com tudo o que nela existe" (Pereira et al. 2015, p. 219).

Nas páginas seguintes, no texto "Os componentes do Sistema Solar" as autoras apresentam o modelo atual de Sistema Solar, o heliocêntrico, no intuito de definir e caracterizar os elementos que o compõem, tais como os planetas, o Sol, os movimentos de rotação e translação e a definição de órbita, que "é o 'caminho' que um astro percorre em sua translação ao redor de outro" (Pereira et al. 2015, p. 221)

No fim da página, um box intitulado "Ciência tem História", apresenta a imagem de Johannes Kepler e uma breve definição, em três linhas, da sua contribuição acerca do formato elíptico das órbitas dos corpos celestes.

No capítulo 15, intitulado "A Terra e a Lua", as autoras fazem uma explanação das estações do ano e sua relação com os hemisférios, norte e sul; os eclipses, solar e lunar, apresentam imagens e sua relação com as fases da lua: cheia, minguante, crescente e nova. Adiante, no box "Ciência tem História", há um texto intitulado "A astronomia e os avanços científicos e tecnológicos". Nesta seção, as autoras abordam a evolução das ideias sobre o Sistema Solar no que tange a definição de modelo geocêntrico e heliocêntrico. Inicia-se com a contribuição de Claudius Ptolomeu ao modelo geocêntrico e Nicolau Copérnico ao modelo heliocêntrico. O motivo que levou Nicolau Copérnico a elaborar um modelo diferente ao geocentrismo 
não foi questionado, apesar das autoras ressaltarem que "essa teoria ocasionou uma reviravolta nos debates científicos da época" (Pereira et al. 2015, p. 245), no entanto, não há detalhes do que seria essa reviravolta e quais foram as controvérsias científicas que houve àquela época.

No manual do professor, as autoras definem os objetivos do box "Ciência tem História", segundo as mesmas, tem o objetivo de "mostrar o processo histórico de construção de conceitos em seus diferentes contextos histórico-sociais de produção, [...] com o objetivo de possibilitar ao aluno a compreensão de que a aceitação ou não de uma teoria tem grande relação com forças sociais [...]” (p. 292). Observa-se que, o box da página 221, em nada se aproxima com essa definição que as autoras propuseram no manual do professor, trata-se de uma informação irrisória da contribuição de Johannes Kepler sobre as órbitas dos planetas, ocupando três linhas. Nos PCNs, observa-se uma aproximação com a fala das autoras propostas no manual do professor, mas que não é contemplada no livro do aluno, que é a "compreensão da Ciência como um processo de produção de conhecimento e uma atividade humana, histórica, associada a aspectos de ordem social, econômica, política e cultural" (p. 33).

Apesar da ausência da História da Ciência como construção humana na temática do Sistema Solar e do contexto no qual essa reviravolta surgiu, no manual do professor as autoras ressaltam (Pereira et al. 2015, p. 260),

A produção científica é fruto do momento histórico em que foi construída. O contexto de sua criação é determinado por uma conjuntura política, econômica e cultural de determinado tempo e lugar. Além disso, influências da história pessoal - do cientista, imprimidas nesse processo, não podem ser ignoradas, pois justificam que as explicações de mundo e as teorias delas resultantes apresentem diferentes abordagens do fenômeno científico.

Nota-se a contradição do que o manual do professor estabelece ao que é exposto no livro didático do aluno.

Um pouco da utilização da tecnologia vigente à época, vem com o surgimento da luneta de Galileu Galilei, em que ele "pode identificar que há manchas no Sol, que existem satélites ao redor de Júpiter e que o planeta Vênus apresenta fases semelhantes às da Lua" (Pereira et al. 2015, p. 245). Em seguida, Johannes Kepler, “comprovou, por cálculos matemáticos, que as órbitas dos planetas são elípticas, e não circulares, como eram apre- sentadas nos modelos de Ptolomeu e Copérnico" (Pereira et al. 2015, p. 245).

Sobre a evolução tecnológica e o uso de suas atribuições à época

Nos séculos seguintes, os avanços científicos e tecnológicos ocorreram de forma mais rápida e o heliocentrismo foi confirmado. A utilização da tecnologia, particularmente dos telescópios, na observação do céu tem possibilitado conhecer, com mais precisão, todo o Sistema Solar (Pereira et al. 2015, p. 245).

O reconhecimento das tecnologias vigentes em cada época faz jus às sugestões que os PCNs de Ciências Naturais propõem, pois, "o seu advento modificou a vida das comunidades humanas, interferiu no ambiente, no desenvolvimento social e, até mesmo, na compreensão do mundo" (Brasil 1998, p. 79).

O livro mostrou-se distante quanto as propostas contidas no manual do professor e as que foram abordadas no livro do aluno, na temática dos modelos de Sistema Solar. Em relação aos PCNs, o livro aproximou-se apenas dos objetivos do ensino da ciência junto ao uso de instrumentos tecnológicos.

\section{Considerações Finais}

A maioria dos livros analisados apresenta aproximações com as sugestões dos PCNs em relação à temática do Sistema Solar, com exceção do livro dois, o que revela que os autores têm preocupação em atender as sugestões do que é prescrito no currículo oficial para a prática escolar. Com relação às propostas e as orientações para o ensino de Ciências que os autores tecem nos manuais dos professores, observamos divergências com o que é abordado no livro do aluno, o que evidencia incoerência interna da obra, em parte dos livros. Somente nos livros um, três e quatro há coerência entre os objetivos do ensino de Ciências, em relação a História da Ciência, introduzidos no Manual do Professor e os conteúdos abordados no livro do aluno.

Um dos papéis da História da Ciência defendido pelos autores que embasam este trabalho é mostrar a ciência como produção humana, seu caráter não neutro de modo a se evidenciar os conflitos. Introduzir o contexto social e religioso em que se deu a produção de determinados conceitos científicos, as idas e vindas da produção da ciência pode colaborar com a aprendizagem de conceitos 
científicos e para a construção de uma visão do processo de elaboração da ciência mais realista. Nesse sentido, consta dos livros um, três, quatro, cinco e seis a apresentação do contexto da época em que houve rupturas e alterações nos modelos do Sistema Solar, particularmente destacando o papel da religião. Exibem ao aluno a existência de controvérsias de ideias e conflitos em se tratando de produção de ciências. Considera-se que há grande relevância em se apresentar tal período da História da Ciência, pois assim pode-se expor a ruptura de uma ideia que perdurou por muitos séculos, afirmando o caráter provisório que a ciência possui. Também considera-se importante promover entre os alunos debates sobre os argumentos que possibilitaram a aceitação seja do modelo geocêntrico seja do heliocêntrico.

Também considera-se ser de grande importância, na temática da evolução do Sistema Solar, analisar com os alunos a contribuição de Ptolomeu ao matematizar o recurso de epiciclos, que veio reparar algumas das falhas do modelo geocêntrico. No entanto, nenhum dos livros didáticos analisados abordou tal fato. Considera-se que a maioria dos livros de ciências naturais do $6^{\circ}$ ano analisados, no tocante à temática do Sistema Solar ainda introduzem a História da Ciência de modo simplificado, sem destacar as questões complexas da época, perspectiva defendida pelos autores com os quais se dialogou.

\section{Referências}

Allchin D. 2004. Pseudohistory and Pseudoscience. Science \& Education, 13:179-195.

Amaral I.A. 2006. Os fundamentos do ensino de ciências e o livro didático. In: Fracalanza H., Megid Neto J. eds 2006. O livro didático de ciências no Brasil. Campinas: Ed. Komedi. p. 81-118.

Amaral P., Oliveira C.E.Q.V. 2011. Astronomia nos livros didáticos de ciências. Uma análise do PNLD2008. Revista Latino-Americana de Educação em Astronomia-RELEA, 12:31-55. URL: http://www.relea. ufscar.br/index.php/relea/article/view/162/208.

Bezerra L.M. 2015. Universos: Ciências da Natureza. São Paulo: Edições SM. 320p.

Brasil. 1998. Secretaria de Educação Média e Tecnologia. Parâmetros Curriculares Nacionais: ciências naturais: terceiro e quarto ciclos. Brasília: MEC/SEMTEC.

Cachapuz A., Gil-Perez D., Carvalho A.M.P., Praia J., Vilches A. 2011. A necessária renovação do ensino de ciências. São Paulo: Cortez. 264p.

Cellard A. 2008. A análise documental. In: Poupart J., Deslauriers J.P., Groulx L.H., Laperriére A., Mayer R., Pires A. A pesquisa qualitativa: enfoques epistemológicos e metodológicos. Petrópolis, RJ: Vozes. p. 295-316.
Delizoicov D., Angotti J.A., Pernambuco M.M. 2011. Ensino de ciências: fundamentos e métodos. São Paulo: Cortez. 368p.

Fracalanza H., Megid Neto J. 2006. O Livro Didático de Ciências no Brasil. Campinas: Ed. Komedi. 224p.

Gewandsznajder F. 2016. Projeto Teláris: Ciências. São Paulo: Ática. 336p.

Gimeno Sacristán J. 1998. O currículo: os conteúdos do ensino ou uma análise de prática. In: Gimeno Sacristán J., Péres Gomes A.I. eds. 1998. Compreender e transformar o ensino. Porto Alegre: Artmed. p. 119-147.

Gimeno Sacristán J. 2000. O currículo: uma reflexão sobre a prática. Trad. Ernani F.F. Rosa. 3 ed. Porto Alegre: Artmed. 352p.

Gowdak D., Martins E. 2015. Ciências Novo Pensar. São Paulo: FTD. 400p.

Langhi R., Nardi R. 2007. Ensino de Astronomia: erros conceituais mais comuns presentes em livros didáticos de Ciências. Cad. Bras. Ens. Física, 24(1):87-111. URL: https://periodicos.ufsc.br/index.php/fisica/article/view/6055/12760.

Lopes S. 2015. Investigar e Conhecer: Ciências da Natureza. São Paulo: Saraiva. 512p.

Neves M.C.D. 2000. A terra e sua posição no universo: formas, dimensões e modelos orbitais. Rev. Bras. Ens. Física, 22(4):557-567.

Passos E., Sillos A. 2015. Tempo de Ciências. São Paulo: Ed. do Brasil. 352p.

Pedrinaci E. 1994. La historia de la geologia como herramienta didáctica. Rev. Enseñanza de las Ciencias de la Tierra, 2(2):332-339.

Pereira A.I., Amador F. 2007. A História da Ciência em manuais escolares de Ciências da Natureza. Rev. Electrónica de Enseñanza de las Ciencias. 6(1):191216.

Pereira A.M., Santana M., Waldhelm M. 2015. Projeto Apoema: Ciências. São Paulo: Ed. do Brasil. 368p.

Praia J.F. 2012. Contributo para uma leitura possível de um percurso profissional. In: Carvalho A.M.P., Cachapuz A.F., Gil-Perez D. 2012. O ensino das ciências como compromisso científico e social: os caminhos que percorremos. São Paulo: Cortez. p. 53-74.

Sillos A., Passos E. 2015. Tempo de Ciências. São Paulo: Ed. do Brasil.

Souza E., Brusi D., Calonge A. 2017. El documento "Alfabetización en Ciencias de la Tierra" como referente para la investigación del potencial didáctico de las ilustraciones geocientificas en los libros de texto de Enseñanza Secundaria. Rev. Enseñanza de las Ciencias de la Terra, 25(3):330-340.

Trevisan R.H., Lattari C.J.B., Canalle J.B.G. 1997. Assessoria na avaliação do conteúdo de astronomia dos livros didáticos de ciências do primeiro grau. Cad. Bras. Ens. Física, 14(1):7-16. URL: https://periodicos.ufsc.br/index.php/fisica/article/ view/7037/15173.

Trindade L. dos S.P., Rodrigues S.P., Saito F., Beltran M.H.R. 2010. História da Ciência e Ensino: alguns desafios. In: Beltran M.H.R., Saito F., Trindade L. dos S.P. 2010. História da Ciência: tópicos atuais. São Paulo: Livr. da Física, p. 119-132.

Trivellato J.J., Trivellato S.L.F., Motokone M.T., Lisboa J.C.F., Kantor C.A. 2015. Ciências. São Paulo: Quinteto Editorial. 400p. 